\title{
A case of Noonan syndrome diagnosed using the facial recognition software (FACE2GENE)
}

\author{
Soo Kyoung Kim ${ }^{1 \oplus}$, So Yoon Jung ${ }^{1 \oplus}$, Seong Phil Bae ${ }^{1 \oplus}$, Jieun $\mathrm{Kim}^{2 \oplus}$, Jeongho Lee ${ }^{1, *} \oplus$ and Dong Hwan Lee ${ }^{1 \oplus}$ \\ 'Department of Pediatrics, Soonchunhyang University Seoul Hospital, Seoul, Korea \\ ${ }^{2}$ Department of Laboratory Medicine, Soonchunhyang University Seoul Hospital, Seoul, Korea
}

\begin{abstract}
Clinicians often have difficulties diagnosing patients with subtle phenotypes of Noonan syndrome phenotypes. Facial recognition technology can help in the identification of several genetic syndromes with facial dysmorphic features, especially those with mild or atypical phenotypes. A patient visited our clinic at 5 years of age with short stature. She was administered growth hormone treatment for 6 years, but her growth curve was still below the 3rd percentile. She and her mother had wide-spaced eyes and short stature, but there were no other remarkable features of a genetic syndrome. We analyzed their photographs using a smartphone facial recognition application. The results suggested Noonan syndrome; therefore, we performed targeted next-generation sequencing of genes associated with short stature. The results showed that they had a mutation on the PTPN11 gene known as the pathogenic mutation of Noonan syndrome. Facial recognition technology can help in the diagnosis of Noonan syndrome and other genetic syndromes, especially in patients with mild phenotypes.
\end{abstract}

Key words: Noonan syndrome, Facial recognition, Biometric identification.

\section{Introduction}

Noonan syndrome is inherited in autosomal dominant manner, with an incidence of 1:1,000 to 1:2,000 [1,2]. Noonan syndrome is associated with several clinical features such as dysmorphic face, specific cardiac defects, short stature, mild mental retardation, and learning disorder [3]. Short stature is common features of patients with Noonan syndrome. Even though weight and length at birth are typically within normal range, about $50 \%$ to $70 \%$ of patients with Noonan syndrome have short statures. Their growth curves usually follow the 3 rd percentile from infancy to childhood, and they have delayed growth spurt during puberty [2].
Patients with Noonan syndrome have specific facial features such as long foreheads, wide-spaced eyes, short broad-based noses, low-set ears, and cupid bow appearance of upper lip [4]. The facial features of patients with Noonan syndrome change with age $[1,3]$. It takes a considerable period of training and a lot of experience to develop the skills necessary to recognize facial dysmorphic features [5]. Facial analysis technologies with deeplearning algorithms can help clinicians identify and diagnose rare genetic disorders with facial dysmorphic features, especially the non-classical or atypical presentations [6].

In this report, we present a case of Noonan syndrome diagnosed and confirmed with the help of the smartphone facial recognition software known as FACE2GENE.

\footnotetext{
Received: 19 November 2019, Revised: 2 December 2019, Accepted: 2 December 2019, Published: 31 December 2019

*Corresponding author: Jeongho Lee, M.D., Ph.D. (iD https://orcid.org/0000-0003-4455-7540

Department of Pediatrics, Soonchunhyang University Seoul Hospital, 59 Daesagwan-ro, Yongsan-gu, Seoul 04401, Korea.

Tel: +82-2-709-9341, Fax: +82-2-709-9135, E-mail: ljh@schmc.ac.kr

Conflict of interest: The authors declare that they do not have any conflicts of interest.

(c) This is an open-access article distributed under the terms of the Creative Commons Attribution Non-Commercial License (http://creativecommons.org/licenses/by-nc/4.0/) which permits unrestricted non-commercial use, distribution, and reproduction in any medium, provided the original work is properly cited.

c) Copyright 2019 by the Korean Society of Medical Genetics and Genomics

www.e-kjgm.org
} 


\section{Case}

A 5-year-old girl was referred to pediatric endocrinology outpatient clinic due to short stature. She was born at $41+2$ weeks of gestation by cesarean section. She is the firstborn in the family and was delivered after a normal pregnancy with no birth injury. At birth, her weight was 3,270 g (10-50th percentile), and her length was $47.6 \mathrm{~cm}$ (3-10th percentile). Her height began to fall below the 3 rd percentile from when she was 3 years old. Her mother's height was $147 \mathrm{~cm}$, her father's height was 173 $\mathrm{cm}$, and the mid-parental height was $153.5 \mathrm{~cm}$. There was no other significant familial history. She had no history of developmental delay or intellectual disability. Basal blood tests including complete blood count, chemistry/electrolyte panel and thyroid function tests were within normal range. Chromosome analysis revealed 46, XX karyotype, so we excluded Turner's syndrome. However, insulin growth factor- 1 was low at $56.75 \mathrm{ng} / \mathrm{mL}$ (reference values for girls at this age: 3 rd percentile $70.2 \mathrm{ng} / \mathrm{mL}$, 10th percentile $115.9 \mathrm{ng} / \mathrm{mL}$ ) and her bone age was 3.5 years old according to Greulich-Pyle method which is slightly delayed for

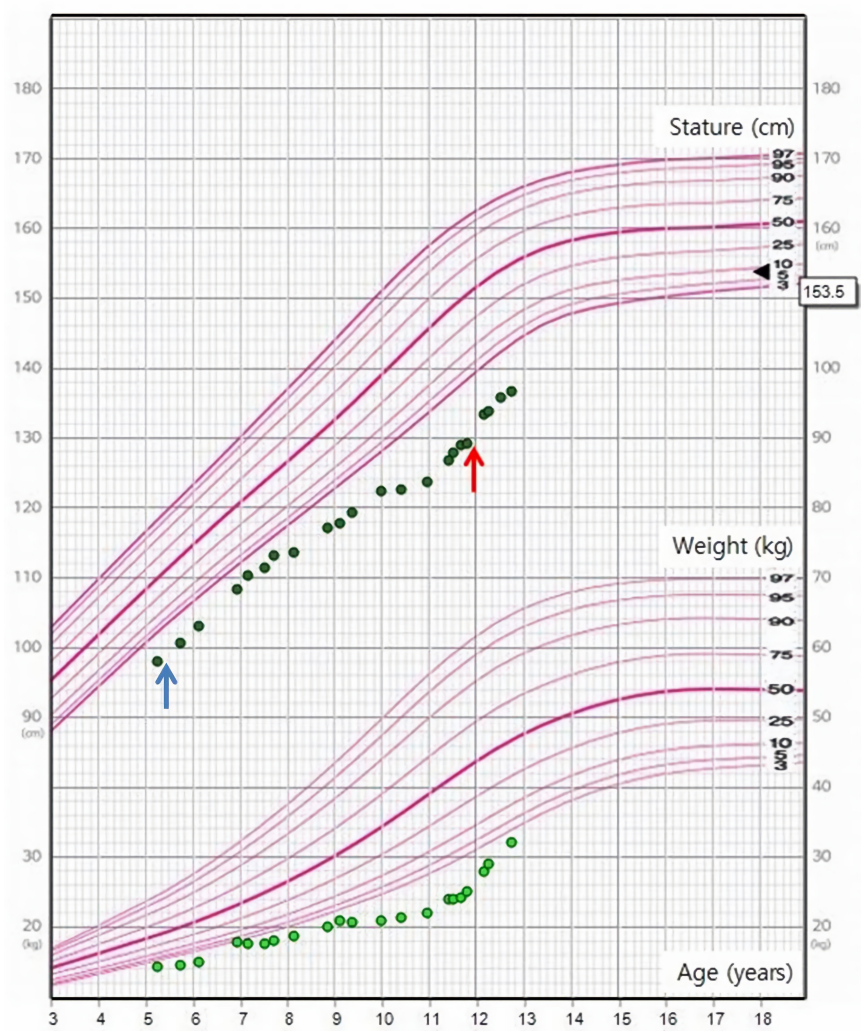

Fig. 1. Growth chart of the patient. The start of growth hormone (GH) replacement (blue arrow). After adjusting the dose of $\mathrm{GH}$ replacement (red arrow), growth velocity increased compared with before changing the dose. her chronologic age. We performed the growth hormone $(\mathrm{GH})$ stimulation test with L-dopa and insulin. The peak GH levels in the L-dopa provocation test and the insulin provocation test were $14.78 \mathrm{ng} / \mathrm{mL}$ and $9.07 \mathrm{ng} / \mathrm{mL}$, respectively. Under the diagnosis of idiopathic short stature, we started the GH treatment. She continued to receive synthetic GH subcutaneously on a daily basis for 6 years, but her growth curve still remained below the 3rd percentile (Fig. 1).

At the age of 11 years and 4 months, she visited our clinic with her mother. She closely resembled her mother, and they both had wide-spaced eyes and short stature which are characteristic of Noonan syndrome. However, there were no other remarkable dysmorphic features, so we analyzed photographs of her face and her mother's face using a smartphone facial recognition application known as FACE2GENE after obtaining parental and patient consent. The result of the analysis suggested that they have Noonan syndrome (Fig. 2), so we performed genetic analysis.

We collected blood sample from the patient and performed genetic analysis using targeted next-generation sequencing of genes associated with short stature. These genes analyzed including COL10A1, COL1A1, COL2A1, COMP, EXT1, FBN1, FGFR1, FGFR2, FGFR3, MATN3, PTPN11 and SOX9.

The result of genetic analysis suggested the patient has a mutation of the PTPN11 gene (c.922A>G; p.Asn308Asp), which was reported in approximately $50 \%$ of Noonan syndrome patients, and we also performed genetic test for the patient's mother and found the same mutation of the PTPN11 gene (Fig. 3).

We confirmed Noonan syndrome based on the results of the genetic tests and further performed work-up for other problems that may accompany Noonan syndrome. Physical examination showed that she has no chest or spine deformities. We

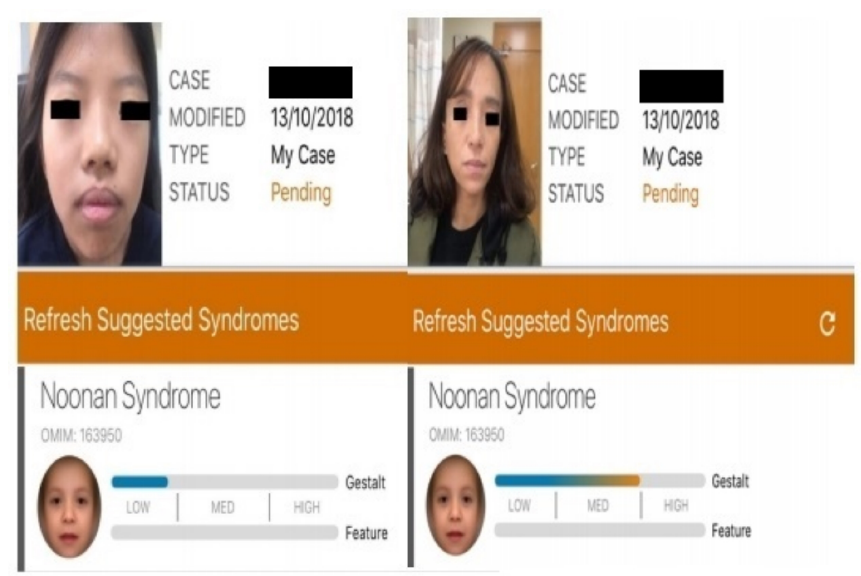

Fig. 2. Pictures of the analysis of the patient's face using a smartphone facial recognition application (FACE2GENE). 


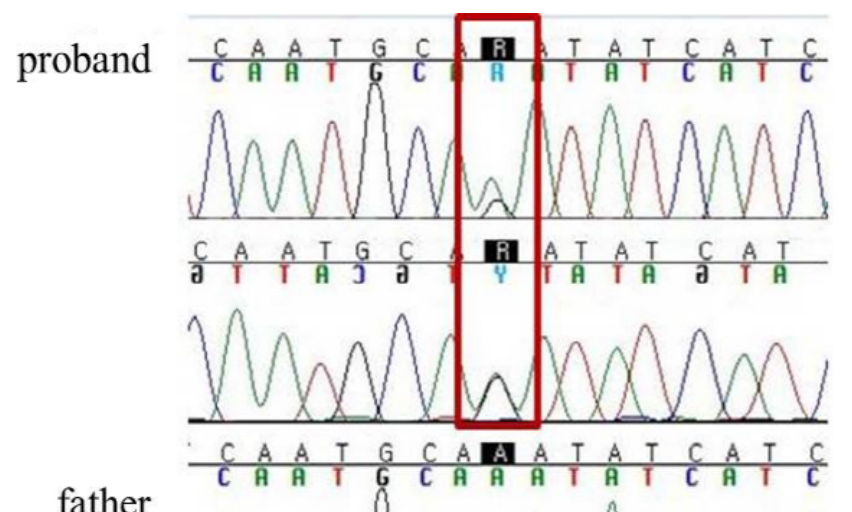

father
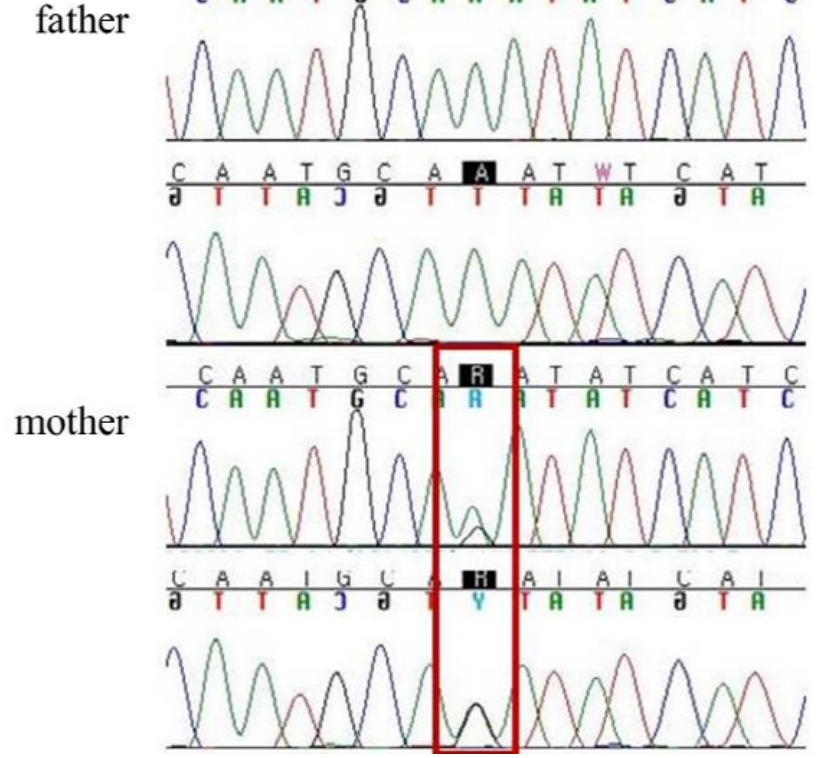

Fig. 3. Sanger sequencing of the proband and her mother showing a missense variation $(c .922 \mathrm{~A}>\mathrm{G})$ resulting in a p.N308D mutation of the PTPN11 gene.

performed blood coagulation test, and polar body morphology assessment to check for hematological problems, and the results were within normal limits. There was no evidence of cardiomegaly or other cardiac disorders based on chestX-ray and echocardiography. After genetic confirmation of Noonan syndrome, we adjusted the dose of GH replacement from $0.041 \mathrm{mg} / \mathrm{kg} /$ day to $0.055 \mathrm{mg} / \mathrm{kg} /$ day and the growth velocity after dose adjustment increased from its value before dose adjustment (from $4.3 \mathrm{~cm} / \mathrm{yr}$ to $7.6 \mathrm{~cm} / \mathrm{yr}$ ) (Fig. 1). We planned regular follow-up assessments of her growth and development. We also planned to annually check for dental, ophthalmological, cardiac, and hematological problems associated with Noonan syndrome.

\section{Discussion}

Diagnosis of Noonan syndrome can be difficult because its phenotypes are highly variable and can change with age [7]. Genetic heterogeneity can cause clinical presentations to vary according to mutations $[8,9]$. Facial analysis technology can be useful in the identification of syndromes with dysmorphic features, especially in patients with atypical presentations [7].

Most studies of Noonan syndrome phenotype are based on European cohorts, but there are relatively fewer studies on nonEuropean populations. Furthermore, studies and guidelines on multiple ethnic cohorts and country-specific data are limited [7]. In this patient, we used a face recognition software called FACE2GENE. This application use technology known as DeepGestalt, a community-driven phenotyping platform collected tens of thousands of patient images and used to recognize hundreds of syndromes. FACE2GENE convert photos of all individuals into a de-identified digital data to protect patient information. Its use has been reported in many genetic syndromes such as Cornelia de Lange syndrome and Angelman syndrome. Since the application data of FACE2GENE is mainly based on European and American populations, there are some limitations to its use for Asian patients. Therefore, further studies on the correlation and usefulness of FACE2GENE in Asian populations and more specific data applicable to specific ethnic groups are necessary [6].

The long-term benefits of $\mathrm{GH}$ replacement in patients with Noonan syndrome are not clear. Such lack of clarity can foster confusion among clinicians and lead to non-uniform treatment plans even in the same country [10]. In a recent study, the importance of early diagnosis and timely initiation of $\mathrm{GH}$ treatment was highlighted as early administration of long-term GH treatment was shown to positively affect height in adults [11].

In Korea, insurance coverage for $\mathrm{GH}$ replacement for short stature is only available for patients with $\mathrm{GH}$ deficiency, Turner syndrome, chronic kidney disease, Noonan syndrome, or PraderWilli syndrome, and for small-for-gestational-age infants. In all other cases, including idiopathic short stature, patients without insurance coverage bear heavy financial burdens for $\mathrm{GH}$ replacement. Hence, our patient had no insurance coverage until she was diagnosed with Noonan syndrome. Furthermore, the general $\mathrm{GH}$ replacement dose for idiopathic short stature is 0.025 to $0.050 \mathrm{mg} / \mathrm{kg} /$ day, but for Noonan syndrome, there is approval from the Korea Food and Drug Administration to increase the dose to $0.066 \mathrm{mg} / \mathrm{kg} /$ day. The growth velocity of our patient improved after her $\mathrm{GH}$ replacement dose was increased. In a randomized double-blind trial on the efficacy and safety of $2 \mathrm{GH}$ doses $(0.033 \mathrm{mg} / \mathrm{kg} /$ day and $0.066 \mathrm{mg} / \mathrm{kg} /$ day) in patients with Noonan syndrome and short stature, greater efficacy was observed in the high dose group than in the low dose group [12].

In conclusion, due to the various clinical manifestations of Noonan syndrome, some patients with mild phenotypes may be 
underdiagnosed or misdiagnosed [7]. Facial recognition technology can help clinicians, especially those with limited experience, to identify and diagnose genetic syndromes with characteristic facial features, thereby facilitating early management of patients [6].

\section{References}

1. Allanson JE, Hall JG, Hughes HE, Preus M, Witt RD. Noonan syndrome: the changing phenotype. Am J Med Genet 1985;21:507-14.

2. Roberts $A E$, Allanson JE, Tartaglia M, Gelb BD. Noonan syndrome. Lancet 2013;381:333-42.

3. Bhambhani V, Muenke M. Noonan syndrome. Am Fam Physician 2014;89:37-43.

4. Lee BH, Yoo HW. Noonan syndrome and RASopathies: clinical features, diagnosis and management. J Genet Med 2019;16:1-9.

5. Hammond $P$. The use of 3D face shape modelling in dysmorphology. Arch Dis Child 2007;92:1120-6.

6. Gurovich Y, Hanani Y, Bar O, Nadav G, Fleischer N, Gelbman D, et al. Identifying facial phenotypes of genetic disorders using deep learning. Nat Med 2019;25:60-4.
7. Kruszka P, Porras AR, Addissie YA, Moresco A, Medrano S, Mok GTK, et al. Noonan syndrome in diverse populations. Am J Med Genet A 2017;173:2323-34.

8. Koh AL, Tan ES, Brett MS, Lai AHM, Jamuar SS, Ng I, et al. The spectrum of genetic variants and phenotypic features of Southeast Asian patients with Noonan syndrome. Mol Genet Genomic Med 2019;7:e00581.

9. Ko JM, Kim JM, Kim GH, Yoo HW. PTPN11, SOS1, KRAS, and RAF1 gene analysis, and genotype-phenotype correlation in Korean patients with Noonan syndrome. J Hum Genet 2008;53:999-1006.

10. Giacomozzi C, Deodati A, Shaikh MG, Ahmed SF, Cianfarani S. The impact of growth hormone therapy on adult height in Noonan syndrome: a systematic review. Horm Res Paediatr 2015;83:167-76.

11. Seo GH, Yoo HW. Growth hormone therapy in patients with Noonan syndrome. Ann Pediatr Endocrinol Metab 2018;23:176-81.

12. Ozono $K_{1}$ Ogata $T$, Horikawa $R$, Matsubara $Y$, Ogawa $Y$, Nishijima $K_{1}$ et al. Efficacy and safety of two doses of Norditropin ${ }^{\circledR}$ (somatropin) in short stature due to Noonan syndrome: a 2-year randomized, double-blind, multicenter trial in Japanese patients. Endocr J 2018;65:159-74. 